\title{
AVALIAÇÃO DA SUSTENTABILIDADE EM HABITAÇÕES DE INTERESSE SOCIAL DO PROGRAMA MINHA CASA MINHA VIDA EM RANCHO QUEIMADO - SC
}

\author{
Aniara Bellina Hoffmann; Lisiane Ilha Librelotto , Dra. (UFSC)
}

\section{INTRODUÇÃO}

A degradação do meio ambiente, a falta de moradias e os altos custos da habitação são apontados como os problemas na atualidade. O Relatório Brundtland (1987) e o relatório final da Cúpula dos Povos de 2012 atestam que a solução é o desenvolvimento sustentável sob os aspectos ambiental, social e econômico. Esta dissertação trata da avaliação da sustentabilidade de Habitações de Interesse Social (HIS) do Programa Minha Casa Minha Vida (PMCMV) na etapa de projeto com foco na seleção de materiais mais importantes da Curva $A B C$ do estudo de casos no município de Rancho Queimado SC. Os objetivos desta dissertação (Hoffmann, 2014), foram: a) Levantar metodologias de avaliação da sustentabilidade de projeto e os principais conceitos envolvidos; b) Determinar curva $A B C$ dos insumos materiais mais representativos do orçamento das habitações selecionadas para a região de escopo; c) Estabelecer a lista de materiais de construção comuns da habitação de interesse social na região de escopo; d) Verificar a flexibilidade da metodologia adotada através da modificação do objeto de avaliação e complementação dos requisitos; e) Verificar a apreensão do método adotado pelos projetistas f) Realizar a avaliação da sustentabilidade em HIS (econômica, social e ambiental) em projetos implantados no município de Rancho Queimado-SC.

\section{METODOLOGIA}

O método utilizado na dissertação partiu do mapeamento dos conceitos envolvidos na avaliação da sustentabilidade de HIS, onde a partir dos conceitos encontrados foi realizada uma pesquisa sobre as avaliações, ferramentas, métodos e guias de sustentabilidade existentes na construção de edificações. Nessa pesquisa, de acordo com o conceito de sustentabilidade definido, foi escolhida a metodologia para aplicação em projeto piloto.

Posteriormente, a aplicação do piloto foi feita no estágio em docência com duas turmas de TEC IV (Tecnologia da Edificação IV) 2013/2 do curso de Arquitetura e Urbanismo da UFSC, para verificar criticamente o comportamento da metodologia e a aplicação por parte dos projetistas.

A partir dos projetos de HIS avaliados no estágio em docência foram selecionadas algumas tipologias para o estudo de casos. Para a aplicação da metodologia do estudo de casos foram selecionados os materiais mais representativos das edificações. Dessa forma foram feitos oito estudo de casos em quatro tipologias diferentes.

Os projetos foram avaliados com implantação hipotética no município de Rancho Queimado - SC. Essa escolha foi feita em virtude da pesquisa já realizada para o Projeto Piloto, de acordo com as necessidades da metodologia 
definida.

Foram realizadas complementações na metodologia selecionada MASP-HIS de forma a contemplar uma visão mais abrangente da sustentabilidade, com foco nos materiais de construção mais representativos de HIS (Figura 1). A partir dela, realizou-se a avaliação da sustentabilidade dos projetos de habitações em Rancho Queimado - SC.

Figura 1: Esquema sintético dos indicadores e índices de sustentabilidade da metodologia MASP-HIS.

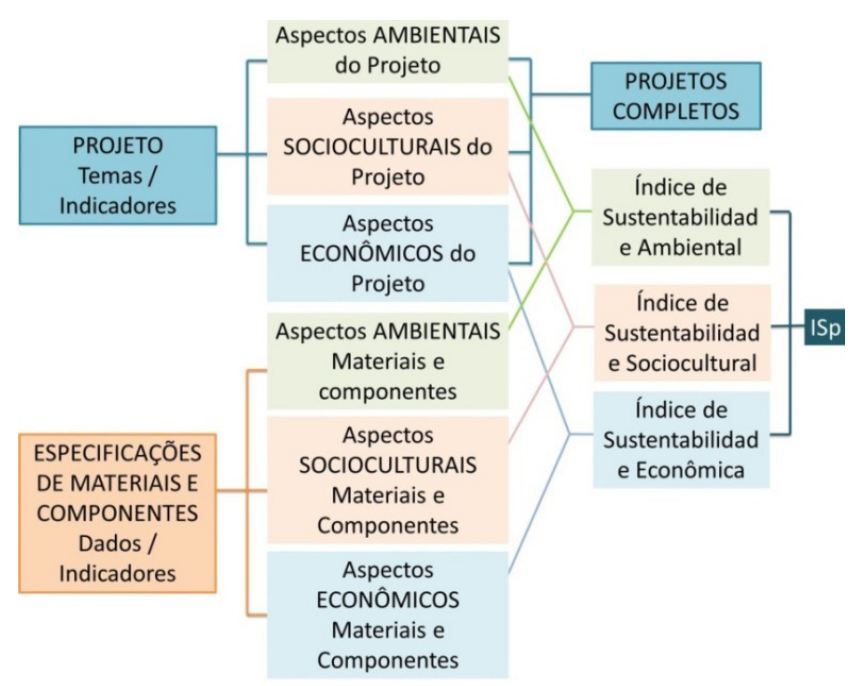

Fonte: CARVALHO, (2009)

\section{RESULTADOS}

A aplicação da metodologia levou a uma pesquisa de dados complexa. É necessário que se crie um banco de dados voltado para a avaliação da sustentabilidade dos materiais para que se possa utilizar a metodologia MASP-HIS de maneira mais dinâmica. Os inventários existentes são incipientes e incompletos. O questionário extenso pode ser simplificado se colocado em programa de computador que gere os resultados, como foi realizado por Carvalho (2009) e nas planilhas em programa Excel geradas para esta dissertação .

A sustentabilidade é um tema complexo, portanto, não se pode quantificar a sustentabilidade de maneira simples. Avaliar cada resultado e cada dado existente no projeto da habitação exige tempo e atenção.

A metologia MASP-HIS mostrou-se sensível nos resultados parciais e variou pouco nos resultados finais. Porém ao multiplicar o custo por m2 para toda a obra, os resultados aparecem. No entanto, deve-se frisar que esta dissertação avaliou projetos semelhantes, em um mesmo local, com os mesmos fornecedores. Portanto essa afirmação é apenas a avaliação desta aplicação.

\section{CONSIDERAÇÕES FINAIS}

A dissertação limitou-se a aplicar a metodologia MASP-HIS com modificações em alguns critérios e com a variação do objetivo para avaliação de materiais. No entanto, dada à complexidade de se avaliar a sustentabilidade de habitações, e qualquer tipo de edificação, o trabalho ficou assim restrito. Comprovou-se a flexibilidade do MASP-HIS e a possibilidade de sua utilização para evolução da avaliação da sustentabilidade de habitações de interesse social, considerando o equilíbrio entre os três aspectos envolvidos. Foram avaliados quatro projetos construidos com sistemas diferenciados, resultando em oito casos. O projeto com sistema em estrutura de concreto e vedação em alvenaria de blocos cerâmicos obteve melhor avaliação no modelo. Os resultados da avaliação dos projetos foram melhores que a avaliação dos materiais.

\section{REFERÊNCIAS}

Bruntland, G. H. (editor). Our Common Future: The World Commission on Environment and Development. Oxford : Oxford University Press. 398 pp. 1987

CARVALHO, Michele T. M. Metodologia para avaliação da sustentabilidade de habitações de interesse social com foco no projeto. 2009. 
241 p. Doutorado (Tese). Departamento de Engenharia Civil e Ambiental, Universidade de Brasília, DF, 2009.

Aniara Bellina Hoffmann. Avaliação da Sustentabilidade na etapa de projeto em habitação de interesse social (HIS): estudo de caso em Rancho Queimado - SC. 2014. Dissertação (Mestrado em Arquitetura e Urbanismo) - Universidade Federal de Santa Catarina, Coordenação de Aperfeiçoamento de Pessoal de Nível Superior. Orientador: Lisiane Ilha Librelotto.

RIO+20 - Conferência Das Nações Unidas Sobre Desenvolvimento Sustentável, 2012. Documentos finais da cúpula dos povos na Rio+20 por justiça social e ambiental. 2012. Disponível em: <http://riomais20sc.ufsc.br/ files/2012/09/ DOCUMENTOS-FINAIS-DA-CUPULA-DOS-POVOS-NA-RIO-20-POS-JUSTI\%C3\%87A-SOCIAL-E-AMBIENTAL.pdf>. Acesso em 23 out. 2012. 